GLOBAL WATER PATHOGEN PROJECT

PART THREE. SPECIFIC EXCRETED PATHOGENS: ENVIRONMENTAL AND EPIDEMIOLOGY ASPECTS

\title{
PARAGONIMUS SPP.
}

\section{Jong-Yil Chai}

Seoul National University College of Medicine

Institute of Parasitic Diseases Korea Association of Health Promotion

Seoul, South Korea

\section{Bong-Kwang Jung}

Institute of Parasitic Diseases Korea Association of Health Promotion

Seoul, South Korea 


\section{Copyright:}

\section{cc) (1) (2) \\ BY SA}

This publication is available in Open Access under the Attribution-ShareAlike 3.0 IGO (CC-BY-SA 3.0 IGO) license (http://creativecommons.org/licenses/by-sa/3.0/igo). By using the content of this publication, the users accept to be bound by the terms of use of the UNESCO Open Access Repository (http://www.unesco.org/openaccess/terms-use-ccbysa-en).

\section{Disclaimer:}

The designations employed and the presentation of material throughout this publication do not imply the expression of any opinion whatsoever on the part of UNESCO concerning the legal status of any country, territory, city or area or of its authorities, or concerning the delimitation of its frontiers or boundaries. The ideas and opinions expressed in this publication are those of the authors; they are not necessarily those of UNESCO and do not commit the Organization.

\section{Citation:}

Chai, J.Y. and Jung, B.K. (2018). Paragonimus spp. In: J.B. Rose and B. Jiménez-Cisneros (eds), Water and Sanitation for the 21st Century: Health and Microbiological Aspects of Excreta and Wastewater Management (Global Water Pathogen Project). (L. Robertson (eds), Part 3: Specific Excreted Pathogens: Environmental and Epidemiology Aspects - Section 4: Helminths), Michigan State University, E. Lansing, MI, UNESCO. https://doi.org/10.14321/waterpathogens.46

Acknowledgements: K.R.L. Young, Project Design editor; Website Design: Agroknow (http://www.agroknow.com)

Last published: August 1, 2018 


\section{Summary}

Human paragonimiasis is caused by nine species of the trematode genus Paragonimus, namely, $P$. westermani, $P$. africanus, $P$. heterotremus, $P$. kellicotti, $P$. mexicanus, $P$. siamensis, $P$. skrjabini, $P$. skrjabini miyazakii, and $P$. uterobilateralis.

The geographical distribution of each species is as follows: $P$. westermani is distributed worldwide (including Oceania and North America), but mostly in Asia, P. africanus in West Africa (Cameroon, Guinea, Nigeria, and Ivory Coast), $P$. heterotremus in Asia (China, Vietnam, Thailand, Laos, and India), $P$. kellicoti in USA and Canada, $P$. mexicanus in Mexico and South America (Peru, Ecuador, Costa Rica, Panama, and Guatemala), P. siamensis in Thailand and Sri Lanka, P. skrjabini in East Asia (China, Thailand, Japan, Vietnam, and India), $P$. skrjabini miyazakii in Japan, and $P$. uterobilateralis in West Africa (Nigeria, Liberia, Guinea, Ivory Coast, and Gabon).

To complete the life cycle of Paragonimus spp., three kinds of hosts, namely, the snail first intermediate host, the crustacean (crabs and crayfish) second intermediate host, and the mammalian definitive host are needed. Eggs liberated from the definitive host contained in the sputum or feces enter the mountain water or sewage water and infect the snails. Cercariae emerging from the snails infect crabs or crayfish to become metacercariae. When mammalian animals eat the crabs or crayfish, the metacercariae develop to adult flukes.

Paragonimiasis is basically a pulmonary disease; however, it can also occur in extrapulmonary sites including the brain and spinal cord. Clinical features of pulmonary paragonimiasis include bloody sputum, cough, chest pain, night sweating, and lethargy, and frequently resemble those of pulmonary tuberculosis. Cerebral or spinal involvements are most common in $P$. westermani, but can also occur in $P$. skrjabini, $P$. skrjabini miyazakii, and $P$. mexicanus. In cerebral paragonimiasis, seizure, headache, visual disturbance, motor and sensory disturbances are the 5 major clinical symptoms.

The most commonly performed diagnostic procedures for paragonimiasis include sputum examinations for eggs and serologic tests to detect circulating antibodies or antigens using ELISA or immunoblotting.

The drug of choice is praziquantel at the dose of $25 \mathrm{mg} / \mathrm{kg}$ three times daily for 2-3 days. In severe infections, a second set of treatment may be needed. Triclabendazole can be used in $P$. uterobilateralis, $P$. mexicanus, and $P$. skrjabini infections, however, its efficacy on $P$. westermani infection, in particular, cerebral infections, remains to be elucidated.

To prevent paragonimiasis, eating undercooked freshwater crab (including the pickled or drunken crab) and crayfish should be avoided. Avoidance of consuming undercooked boar meat is also recommended in endemic areas. Sanitary treatment of wastewater which may contain the eggs of Paragonimus spp. will help to block their life cycles.

\subsection{Epidemiology of the Disease and Pathogen}

Human paragonimiasis is caused by flukes of the trematode genus Paragonimus. They can infect the lungs as well as extrapulmonary sites, including the thorax, abdomen, skin, brain, spinal cord, and other miscellaneous organs and tissues. Taxonomically, more than 56 different Paragonimus species have been described in the literature; however, 16 to 17 species were found synonymous with other species and 36 species are considered to be valid (Blair et al., 1999; Narain et al., 2010; Chai, 2013a). Among them, human infections are caused mainly by 9 species, which include $P$. westermani, $P$. africanus, $P$. heterotremus, P. kellicotti, $P$. mexicanus, $P$. siamensis, $P$. skrjabini, $P$. skrjabini miyazakii, and $P$. uterobilateralis (Table 1) (Chai, 2013a). Most of human paragonimiasis cases occur in Asia, Africa, and North and South America (Narain et al., 2010; Chai, 2013a).

Table 1. Paragonimus spp. reported from humans.

\begin{tabular}{|c|c|c|c|}
\hline Country of current distribution & $\begin{array}{l}\text { Country of first } \\
\text { report }\end{array}$ & Species of Paragonimus & Synonyms* \\
\hline Cameroon, Guinea, Nigeria, Ivory Coast & West Cameroon & P. africanus & \\
\hline $\begin{array}{l}\text { Cameroon, Nigeria, Liberia, Guinea, } \\
\text { Ivory Coast, Gabon }\end{array}$ & Cameroon & P. uterobilateralis & \\
\hline China, Thailand, Japan, Vietnam, India & China (Guangdong) & P. skrjabini (skrjabini) & $\begin{array}{l}\text { P. hueitungensis, } P \text {. } \\
\text { szechuanensis, } P . \\
\text { veocularis }\end{array}$ \\
\hline China, Vietnam, Laos, Thailand & China (Guangxi) & P. heterotremus & P. tuanshanensis \\
\hline $\begin{array}{l}\text { India, China, Taiwan, Korea, Japan, } \\
\text { Southeast Siberia, Vietnam, Sri Lanka, } \\
\text { Nepal, Pakistan, Papua New Guinea, } \\
\text { USA }\end{array}$ & India & P. westermani & $\begin{array}{c}\text { P. assymetricus, } P \text {. } \\
\text { edwardsi, } P \text {. filipinus, } P \text {. } \\
\text { macacae, } P \text {. } \\
\text { philippinensis, } P \text {. } \\
\text { pulmonalis, } P . \\
\text { ringer }\end{array}$ \\
\hline Japan & Japan & P. skrjabini miyazakii & P. miyazakii \\
\hline
\end{tabular}




\begin{tabular}{|c|c|c|c|}
\hline Country of current distribution & $\begin{array}{c}\text { Country of first } \\
\text { report }\end{array}$ & Species of Paragonimus & Synonyms* \\
\hline $\begin{array}{l}\text { Mexico, Peru, Ecuador, Costa Rica, } \\
\text { Panama, Guatemala }\end{array}$ & Mexico & P. mexicanus & $\begin{array}{l}\text { P. ecuadoriensis, } P \text {. } \\
\text { peruvianus }\end{array}$ \\
\hline Thailand, Sri Lanka, New Guinea & Thailand & P. siamensis & \\
\hline USA, Canada & USA (midwest) & P. kellicotti & \\
\hline
\end{tabular}

The majority of the above information was obtained from Blair et al. (1999) and Chai (2013a); *The same (invalid) species as that of the left column.

\subsection{Global Burden of Disease}

\subsubsection{Global distribution}

The global burden of paragonimiasis cases has been estimated to be about 20 million infected people globally (Toscano et al., 1994; Blair et al., 1999) and 293 million people at risk (Keiser and Utzinger, 2005; World Health Organization, 2015a) (Figure 1). However, these may be far underestimates (Chai, 2013a). In some areas, the prevalence shows a decreasing tendency, but in others new endemic foci are discovered or an increasing trend of infection is notified due to an increase in consumption of crabs (Chai, 2013a). The prevalence is in general higher in men than in women, and higher in young children than in adults (Walker and Zunt, 2005).

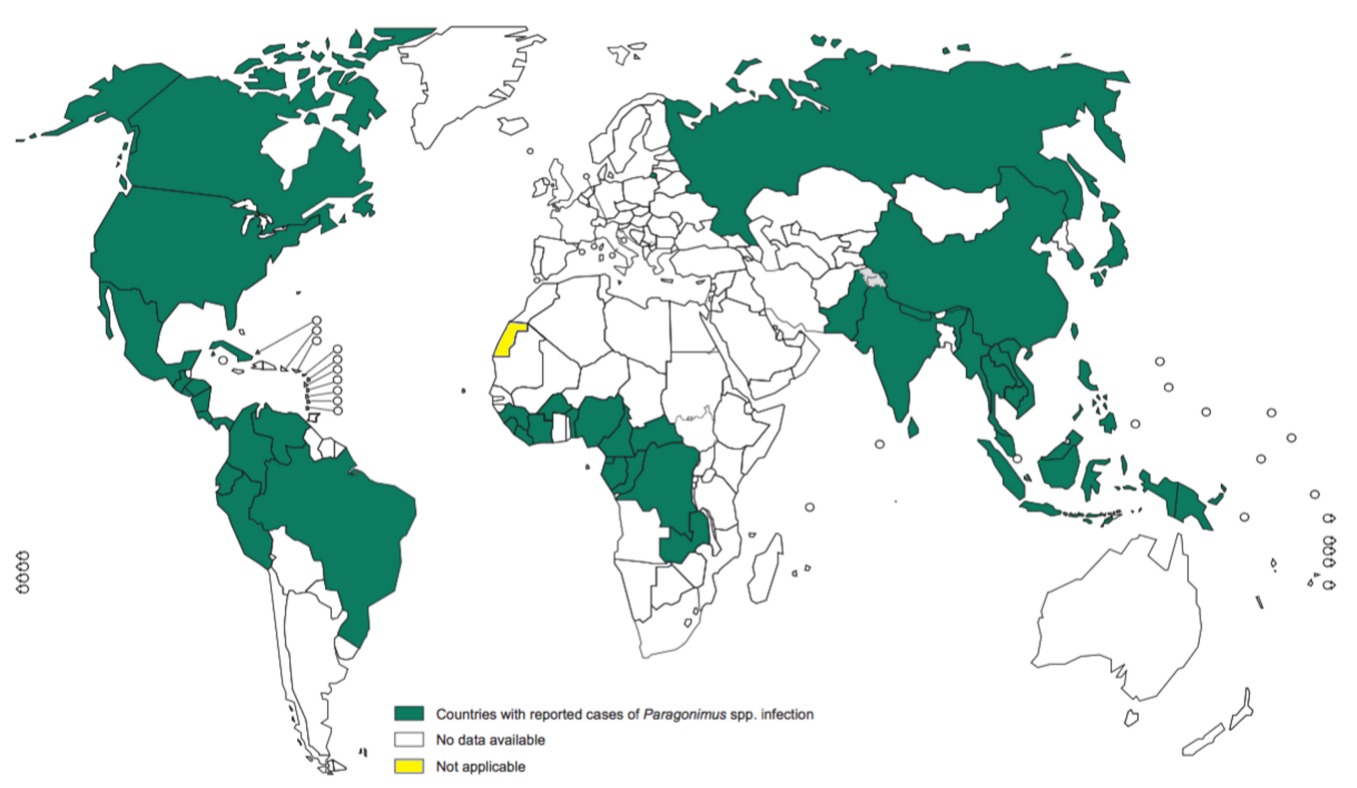

Figure 1. Worldwide distribution of paragonimiasis from WHO report in 2015 ( World Health Organization, 2015a)

\subsubsection{Morbidity, DALYs}

\subsubsection{Morbidity}

Paragonimiasis generally causes considerable degrees of morbidity and, in rare occasions, mortality. Only a few cases whose worm burden is very low (with only 1-2 worms) may undergo subclinically. The acute phase of paragonimiasis (pulmonary and extrapulmonary types) consists of various disease manifestations, such as diarrhea, abdominal pain, fever, cough, urticaria, hepatosplenomegaly, pulmonary abnormalities, and eosinophilia (CDC, 1999). In pulmonary infections, general acute symptoms include fever $(100 \%)$, cough $(100 \%)$, weight loss $(56 \%)$, malaise $(56 \%)$, chest pain $(44 \%)$, dyspnea (44\%), myalgia (44\%), and night sweats (44\%) (CDC, 2010). In the chronic phase, pulmonary manifestations include cough, expectoration of discolored sputum, hemoptysis, and chest radiographic abnormalities; these symptoms could be confused with TB (CDC, 1999). In abdominal paragonimiasis, the worms may cause less definite symptoms, but intra-abdominal masses may be palpable (Meyers and Neafie, 1976), and abdominal pain, diarrhea, abdominal rigidity, and tenderness may be presented (Choi, 1990). In urinary infections, urinary frequency and dysuria may occur (Choi, 1990). In cerebral infections, seizure, headache, visual disturbance, motor and sensory disturbances, optic atrophy, mental deterioration, hemiplegia, hemi-hypalgesia, and homonymous hemianopsia may occur $(\mathrm{Oh}, 1969)$. In spinal 
paragonimiasis, weakness of the legs, paravertebral radicular pain, urinary difficulty, and sensory and motor disturbances in the lower extremities may occur (Oh, 1968b; Choi, 1990).

\subsubsection{DALYs}

The etiological agents of foodborne illnesses of high priority include Paragonimus spp., Clonorchis sinensis, intestinal trematodes (Fasciolopsis buski, Heterophyes spp., Metagonimus spp.), Opisthorchis spp., and Fasciola spp. (Table 2) (World Health Organization, 2015b).
Paragonimus spp. cause a foodborne burden of 1.0 million DALYs (Havelaar et al., 2015). Table 2 shows the global number of Paragonimus spp. infected patients through 3 parameters of years lost to disability (YLD $=1,033,097$ ), years of life lost (YLL $=15,535)$, and disability-adjusted life years (DALYs $=1,048,937$ ). In 2005, the number of global deaths due to paragonimiasis was estimated to be 244 cases, and $10 \%$ case fatality for cerebral infections (Fürst et al., 2012). The high number of DALYs represents that Paragonimus spp. are one of the most important species from the public health aspects among the various foodborne trematodes.

Table 2. Median global number of illnesses, deaths, years lived with disability (YLD), years of life lost (YLL), and disability-adjusted life years (DALY) due to foodborne ${ }^{a}$ trematodes, including Paragonimus spp.

\begin{tabular}{|c|c|c|c|c|c|}
\hline & Foodborne illnesses/year & $\begin{array}{c}\text { Foodborne } \\
\text { deaths/year }\end{array}$ & Foodborne YLD & Foodborne YLL & Foodborne DALY \\
\hline $\begin{array}{l}\text { Paragonimus } \\
\text { spp. }\end{array}$ & 139,238 & 250 & $1,033,097$ & 15,535 & $1,048,937$ \\
\hline $\begin{array}{l}\text { Clonorchis } \\
\text { sinensis }\end{array}$ & 31,620 & 5,770 & 219,637 & 302,160 & 522,863 \\
\hline Fasciola spp. & 10,635 & 0 & 90,041 & 0 & 90,041 \\
\hline $\begin{array}{l}\text { Intestinal } \\
\text { flukes }^{b}\end{array}$ & 18,924 & 0 & 155,165 & 0 & 155.165 \\
\hline $\begin{array}{l}\text { Opisthorchis } \\
\text { spp. }\end{array}$ & 16,315 & 1,498 & 102,705 & 85,364 & 188,346 \\
\hline
\end{tabular}

${ }^{\mathrm{a}}$ Trematode parasites contracted by eating food materials; ${ }^{\mathrm{b}}$ Including species of the families Echinostomatidae, Fasciolidae, Gymnophallidae, Heterophyidae, Nanophyetidae, Neodiplostomidae, and Plagiorchiidae (depending on data availability) (WHO, 2015b).

\subsubsection{Symptomatology}

1.1.3.1 Pathogenesis of pulmonary and extrapulmonary paragonimiasis

When humans consume crab or crayfish meat containing metacercariae of Paragonimus spp. (originating from the crabs ingesting infected snails due to fecally contaminated water), the metacercariae excyst in the duodenum and penetrate into the intestinal wall; during this process they mature into juvenile flukes. The juvenile flukes enter immediately the inner wall (abdominal muscle) of the abdominal cavity, and after 5-7 days development there, they reappear in the abdominal cavity (Yokogawa, 1965). Then, the worms penetrate the diaphragm and enter into the pleural cavity in about 14 days after infection (Yokogawa, 1965). In the pleural cavity, 2 worms mate and then move to the lung parenchyma where a fibrous cyst (= worm cyst or worm capsule) develops around the worms (Narain et al., 2010; Chai, 2013a). They exchange sperms and produce eggs within the worm cyst, which accumulate for some time in acute stages but in chronic stages when tissue necrosis occurs around the cyst, then the eggs escape from the cyst into small bronchioles and eventually to the external environment via sputum or feces (Yokogawa, 1965; Blair et al., 1999). Because of this complex migration route, worms may go astray and may locate in abnormal locations; thus, patients may undergo variable clinical types, including pulmonary, thoracic, abdominal, cerebral, spinal, and cutaneous paragonimiasis (Nakamura-Uchiyama et al., 2002; Singh and Sugiyama, 2008; Chai, 2013a). In heavy infections, a combined pulmonary and extrapulmonary involvement may occur (Nakamura-Uchiyama et al., 2002).

The extrapulmonary migration of Paragonimus worms has been suggested to occur due to several reasons. The most important reason is the complex migration route of the worms, i.e., from the intestinal lumen to the intestinal wall, abdominal cavity, abdominal muscle, back to the abdominal cavity, diaphragm, pleural cavity, and lung parenchyma (Chai, 2013a). Another reason suggested was seeking for sexual partners to exchange sperms, for example, in $P$. westermani (Miyazaki, 1991). P. skrjabini miyazakii adult and juvenile flukes frequently wander far from the lungs and thoracic region (Narain et al., 2010). Similarly, $P$. skrjabini ( $P$. skrjabini skrjabini) worms more frequently cause cutaneous or cerebral involvements than causing 
pulmonary lesions (Nakamura-Uchiyama et al., 2002). The skin lesions usually contain juvenile flukes (NakamuraUchiyama et al., 2002). Extrapulmonary infections are common in $P$. westermani, $P$. skrjabini, $P$. skrjabini miyazakii, and $P$. mexicanus; therefore, humans are considered to be a less suitable host for these Paragonimus spp. infection (Chai, 2013a). The thoracic and abdominal muscles, brain, spinal cord, eyes, periorbital tissue, skin, subcutaneous tissues, heart muscles, mediastinum, breast, bone marrow, liver, spleen, greater omentum, appendix, peritoneal cavity, pericardial cavity, ovary, uterus, scrotum, inguinal regions, thigh, and urinary tract have been reported to be the ectopic foci commonly reported in the literature (Yokogawa, 1965; Oh, 1968a; Choi, 1990; Blair et al., 1999; Chai et al., 2011).

In $P$. westermani, the brain is the most commonly involved organ other than the lungs and pleura (Choi, 1990). The mechanisms and route of worm migration to the brain are not well understood. However, it was suggested that Paragonimus larvae migrate through loose perivascular connective tissues around the carotid artery or jugular vein and enter the posterior circulation via the foramen of the skull base (Oh, 1969). Excretory-secretory antigens may be toxic and allergic and important in eliciting immune responses of the host (Lee et al., 1989a). In particular, in extrapulmonary paragonimiasis, these toxic or allergic metabolites from worms may be highly pathogenic (Blair et al., 1999); however, this aspect needs further attention.

\subsubsection{Pulmonary and thoracic paragonimiasis}

In pulmonary infections, worms usually pair and lie in worm cysts of host origin (1-2 cm in diameter) within the lung parenchyma (Blair et al., 1999). According to chest radiography findings, the lung lesions can be classified into infiltrative, nodular, and cavitating shadow types, or combination of these types (Nakamura-Uchiyama et al., 2002). As there is no exit from the worm cyst in early stages of infection, eggs as well as excretes, metabolic products, and tissue debris gather progressively within the cyst, and the cyst is distended, and consequently, the cyst wall becomes most thick and fibrotic (Yokogawa, 1965). In chronic stages, the cyst wall eventually becomes necrotic, and the cyst ruptures liberating the eggs and debris, including blood and necrotized tissues, into the bronchiole and then the bronchus. At this stage, eggs can be demonstrated in the blood-tinged portion of the sputum in the laboratory (Chai et al., 2011). This kind of pulmonary paragonimiasis can be seen typically in patients infected with $P$. westermani, $P$. africanus, $P$. heterotremus, $P$. kellicotti, $P$. mexicanus, and $P$. uterobilateralis (Blair et al., 1999). However, in P. skrjabini and P. skrjabini miyazakii infections, humans might not be a suitable host; and the worms can rarely cause pulmonary infections (Okamoto et al., 1993; Chai, 2013a). Pulmonary paragonimiasis is often associated with infections in the pleura, thoracic cavity, and diaphragm (Chai, 2013a). Some worms in the pleural cavity fail to enter the lung parenchyma and may stay there or enter the pleura or diaphragm causing pleural or thoracic paragonimiasis; in such cases, pleural effusion, pneumothorax, pleural thickening, and secondary bacterial infections may occur (Narain et al., 2010).

In acute stages of infection, the worms are in the process of migration from the peritoneal cavity, through the abdominal wall, to the pleural cavity and lungs (Chai, 2013a). At 2 to 15 days after infection, the earliest possible manifestations include abdominal pain, fever, chill, and diarrhea, which are more common in heavy infections (Choi, 1990; Nakamura-Uchiyama et al., 2002; Procop, 2009). As the next step, chest pain, fatigue, and urticaria may develop (Choi, 1990). Eosinophilia (up to 25\%) can occur at 2 months after infection (Choi, 1990; Procop, 2009). However, patients may be asymptomatic during the early stages (Procop, 2009). The chronic stage occurs when the worms migrate to their final destination in the lung parenchyma where adult worms are paired in a worm cyst and eggs are produced (Procop, 2009). At this stage, pleuritic chest pain, pleural effusion, dyspnea, bronchiectasis, pneumothorax, interstitial pneumonitis, transient hemorrhage, and bronchopneumonia may occur (Procop, 2009). The most common and important findings in chronic stages include chronic cough, rusty-colored sputum (= hemoptysis), recurrent hemoptysis, chest pain, dyspnea, fever, and crepitation (Choi, 1990; Im et al., 1993; Nakamura-Uchiyama et al., 2002). The cough is dry at first but later becomes productive with blood-tinged, tenaceous sputum, and the sputum smells like rotten fish (Choi, 1990; Chai, 2013a). In chest radiographs, cavitating lesions sometimes called as 'ring shadows' or 'cysts' are commonly seen (Im et al., 1993). Among Korean and Japanese pulmonary paragonimiasis patients, pleural effusion is encountered in about $70 \%$ of the cases (Im et al., 1993; Nakamura-Uchiyama et al., 2001). The severity of clinical manifestations may depend on the location of the worm cyst, the number of cysts, and any associated sequelae (Procop, 2009).

\subsubsection{Abdominal paragonimiasis}

Abdominal paragonimiasis is defined as Paragonimus spp. infection in organs and tissues located in the abdominal cavity and adjacent areas (Chai, 2013a). The organs that can be affected include the abdominal wall (muscle), peritoneal cavity, liver, spleen, pancreas, heart, greater omentum, appendix, ovary, uterus, scrotum, inguinal regions, thigh, and urinary tract (Chai, 2013a). Abdominal paragonimiasis is probably more common than cerebral and spinal infections; however, these infections are frequently asymptomatic or only mildly symptomatic (Meyers and Neafie, 1976). In this type of paragonimiasis, the worms generally cause less definite symptoms (Choi, 1990). However, an intra-abdominal mass may be palpable (Meyers and Neafie, 1976), and upon deep palpation, dull abdominal pain, moderate abdominal rigidity, and tenderness may be presented (Choi, 1990). Abdominal abscess can be a major problem in some patients (Kim et al., 2017a). When the intestinal wall is involved, symptoms such as diarrhea may occur, and eggs may be detected in stool (Choi, 1990). In urinary infections, urinary frequency and dysuria may occur as the chief complaints (Choi, 1990). When female genital organs are affected, sterility can occur (Hong et al., 1982). The heart, mediastinum, and breast are 
also occasionally affected (Chai, 2013a). However, when the liver, pancreas, or spleen is involved, clinical symptoms related to these organs may be seldom encountered (Meyers and Neafie, 1976).

\subsubsection{Cerebral paragonimiasis}

Various neurological signs and symptoms ranging from meningitis to dementia and seizures can occur in cerebral paragonimiasis (Oh, 1969). Five major symptoms include seizure (Jacksonian type), headache, visual disturbance, motor and sensory disturbances, and 5 major signs are optic atrophy, mental deterioration, hemiplegia, hemihypalgesia, and homonymous hemianopsia (Oh, 1969). Meningitis is one of the most predominant manifestations in cerebral paragonimiasis (Oh, 1968b). Intracranial hemorrhage can also occur though rare in the incidence (Brenes et al., 1982; Choo et al., 2003). In a few cases, cerebral paragonimiasis can be accompanied by other intracranial diseases (Hayashi et al., 1986; Kim et al., 2000). However, even in endemic foci, paragonimiasis is ranked quite low among the differential diagnosis of patients having cerebral symptoms. Those symptoms are frequently attributed to different diseases, such as infantile paralysis, cerebral hemorrhage, encephalitis, or meningitis; however, in many of such cases the actual causative agent is Paragonimus worms (Choi, 1990). In skull radiography studies, cerebral calcification is the most commonly encountered finding, and temporal, occipital, and parietal lobes of the brain are the predilection sites (Oh, 1968c). The symptoms that are usually seen in cerebral tumors might also be observed in cerebral paragonimiasis (Choi, 1990).

Cerebral paragonimiasis occurs most commonly in $P$. westermani infection (Chai, 2013a). However, it can also occur in P. skrjabini (Zhong et al., 1981), P. skrjabini miyazakii (Miyazaki, 1991), and P. mexicanus infections (Brenes et al., 1982; Procop, 2009). In P. westermani, cerebral paragonimiasis cases account for about $1 \%$ of all paragonimiasis patients (Oh, 1969). In many instances, cerebral paragonimiasis occurs to be accompanied by pleuropulmonary infection (Oh, 1969) and is frequently lifethreatening (Kusner and King, 1993). Cerebral paragonimiasis tends to occur more commonly in men and children than in women and adults; it seems that men and children are more susceptible to this type of Paragonimus infection than women and adults (Yokogawa, 1965; Choi, 1990).

The major pathological findings encountered in cerebral paragonimiasis include early granulomatous lesion and later mass formation with calcification and liquefaction, surrounded by the fibrous cyst (Choi, 1990). In sections of the brain abscess cavity, adult worms may not be seen because of early disintegration, and only irregularly shaped eggs are often observed (Choi, 1990). The lesions are most commonly seen in the cerebral cortex, followed by the subcortex, cerebellum, thalamus, and basal ganglia (Oh, 1969; Procop, 2009); they vary in size and may eventually become calcified (Blair et al., 1999). Occipital and temporal lobes are most frequently affected, which supports the suggestion that the major migration route is through the perivascular soft tissue around the carotid artery or jugular vein (Walker and Zunt, 2005). Intracerebral hemorrhage may occur in some patients with cerebral paragonimiasis (Koh et al., 2012). In a few instances, egg embolism may be one of the pathogenetic mechanisms of the brain lesions (Oh, 1969). The histopathologic findings vary greatly from case to case; however, despite this variance, there are 3 distinct histopathological forms; meningoencephalitic form (stage I), granulomatous form (stage II), and organizationcalcification form (stage III) (Oh, 1969). In the lesion, 3 layers are generally recognized; a deep central layer containing eggs, giant cells, and Charcot-Leyden crystals, a middle layer consisting of connective tissues, and an outer layer showing infiltrations of plasma cells, lymphocytes, and eosinophils (Yokogawa, 1965).

\subsubsection{Spinal paragonimiasis}

Compared with cerebral infections which are quite common, spinal paragonimiasis is relatively rare $(\mathrm{Oh}$, 1968a). In spinal paragonimiasis, weakness of the legs, paravertebral radicular pain, urinary sphincter disturbance and urinary difficulty, sensory symptoms, including paresthesia and numbness in the legs, motor disturbances in the lower extremity, and a positive Babinski sign are the common symptoms and signs (Oh, 1968b; Choi, 1990). A typical course of spinal paragonimiasis is as follows: at the disease onset weakness of the legs begins which is followed by a slowly developing spastic paraplegia with sphincter disorder (Oh, 1968b). The first documented case was a Korean patient reported in 1917 who had paraplegia and was suspected to have a tumor in the spinal cord (Oh, 1968a). The patient was dead, and extradural cysts were found at autopsy (Oh, 1968a). The cyst contained Paragonimus eggs, Charcot-Leyden crystals, and inflammatory products (Oh, 1968a). Thereafter, in Korea, more than 20 cases have been documented (Oh, 1968a; Kim et al., 2011). In Japan, total 4 cases were reported until the 1960s, and in China, total 17 cases were documented during 1957-1958 (Oh, 1968a). The predilection site of spinal paragonimiasis is extradural areas of the thoracic level (Choi, 1990). The histopathological findings are similar to those of cerebral paragonimiasis (Choi, 1990).

\subsubsection{Cutaneous and subcutaneous paragonimiasis}

Cutaneous and subcutaneous paragonimiasis are particularly rare compared to pleuropulmonary and other ectopic paragonimiasis (Chai, 2013a). These types may occur without pleuropulmonary involvement (Jiang et al., 2015). Cutaneous and subcutaneous paragonimiasis accounts for about $16 \%$ of extrapulmonary cases caused by the aberrant invasion of the lung fluke larva (Singh and Sugiyama, 2008). This aberrant migration of juvenile worms forms migratory subcutaneous nodules (Nagayasu et al., 2015). The nodules initially appear on the chest or abdominal wall and then gradually migrate to the inguinal region, genitalia, and lower limbs (Nagayasu et al., 2015). The characteristics of nodules are mobile, non-tender, and firm in consistency, and nodules grow up to $2-5 \mathrm{~cm}$ in diameter (Narain et al., 2010). Rarely, nodules remain at the location without further migration (Chung and Chao, 
1962). P. westermani can cause abscesses and ulcers in the skin or subcutaneous tissues, and $P$. skrjabini causes migrating subcutaneous nodules (Meyers and Neafie, 1976). According to a review of paragonimiasis cases in Japan, 19 of 384 cases (4.9\%) were reported to have cutaneous paragonimiasis (Nagayasu et al., 2015).

\subsection{Taxonomic Classification of the Agents}

\subsubsection{Taxonomy}

The lung flukes of public health importance, Paragonimus spp., belong to the trematode family Troglotrematidae. More than 60 different species have been described in this genus (Blair et al., 1999; Narain et al., 2010; Doanh et al., 2013). Among them, 16-17 species were synonymized with the others (Blair et al., 1999), and 36 species were regarded as valid or potentially valid. Nine among them were reported from human infections (Narain et al., 2010; Wang et al., 2011; Sugiyama et al., 2013) (Table 1). A new species, proposed as $P$. pseudoheterotremus, was reported from an experimentally infected cat with metacercariae from freshwater crabs in Thailand (Waikagul, 2007). More recently, in Vietnam, 4 new species, including $P$. vietnamensis, $P$. proliferus, $P$. bangkokenis, and $P$. harinasutai, have been identified by a combination of morphological and molecular studies (Doanh et al., 2013). However, human infections with these species are yet unknown. In addition, in Costa Rica, morphological and molecular characterizations of Paragonimus caliensis metacercariae suggested that $P$. caliensis is a separate species from $P$. mexicanus (Hernádez-Chea et al., 2017). However, human infections with $P$. caliensis have not been identified.

The taxonomic classification of Paragonimus spp. can be done using morphological as well as molecular characteristics of each species (Narain et al., 2010; Chai, 2013a; Sugiyama et al., 2013). The morphological keys of major importance included the size and shape of adult flukes, metacercariae, and eggs, relative size of the oral and ventral suckers, the branching patterns of the ovary and testes, and the spination of tegumental spines (Chai, 2013a; Sugiyama et al., 2013). The molecular techniques used for differentiation of Paragonimus spp. included PCR, DNA sequencing, RFLP, PCR-RFLP, multiplex PCR, random amplified polymorphic DNA (RAPD), and DNA hybridization (Narain et al., 2010; Sugiyama et al., 2013; Doanh et al., 2013).

As the clinical and epidemiological significance is the highest for $P$. westermani, this species is described first, and then the other 8 species is described in alphabetical order of the species name, from $P$. africanus to $P$. uterobilateralis.

\subsubsection{Paragonimus westermani}

This lung fluke was first discovered in the lungs of a Bengal tiger that died in the Zoological Garden in Amsterdam (Chai, 2013a). Since then, this species has been reported mostly from Asia, including China, Taiwan, Korea, Japan, Southeast Siberia, the Philippines, Malaysia, Thailand, Cambodia, Laos, Vietnam, Sri Lanka, India, Nepal, and Pakistan (Blair et al., 1999; Narain et al., 2010). However, recently, this species was discovered also in Papua New Guinea (Owen, 2005) and USA (Lane et al., 2009; Fried and Abruzzi, 2010; Boland et al., 2011). Natural definitive hosts other than humans include monkeys, dogs, foxes, wolves, cats, tigers, leopards, pigs, and rats (Blair et al., 1999). Freshwater snails, such as Semisulcospira spp. and Malanoides tuberculata, serve as the first intermediate host (Blair et al., 1999). Freshwater crayfish Cambaroides spp. and freshwater crabs Eriocheir spp. and a variety of crab species belonging to the family Potamidae or Parathelphusidae are the second intermediate hosts (Blair et al., 1999). One of the most important morphological characters discriminating $P$. westermani from other Paragonimus species is the patterns of lobation of the ovary and testes (Miyazaki, 1991). The ovary of $P$. westermani has 6 simple lobes, whereas that of $P$. mexicanus or Paragonimus ohirai possesses many delicate branches (Miyazaki, 1991).

\subsubsection{Paragonimus africanus}

This lung fluke species was first described from the mongoose in Cameroon and now known to distribute in Guinea, Cameroon, Nigeria, and Ivory Coast (Narain et al., 2010). Its natural definitive hosts include the black mongoose, civet, drill, and dog (Aka et al., 2008). The aquatic snails Potadoma freethii or Melania spp. are the first intermediate host, and freshwater crabs Liberonautes and Sudanonautes spp. are the second intermediate host (Aka et al., 2008). Its morphological characters include the followings: the distinctly larger oral sucker than the ventral sucker, the delicately branched ovary, and the highly branched testes which is significantly larger than its ovary (Narain et al., 2010).

\subsubsection{Paragonimus heterotremus}

This lung fluke species was first discovered from rats in China and now known to be distributed in China, Vietnam, Laos, Thailand, and India (Singh et al., 2009; Narain et al., 2010). In Thailand, dogs and cats were also found to be infected with this lung fluke (Miyazaki and Vajrasthira, 1967). The freshwater snails, Assiminea spp., Oncomelania spp., and Tricula gregoriana, serve as the first intermediate host, and the freshwater crab, Esanthelphusa dugasti and Siamthelphusa paviei (Thailand) and Potamon flexum and Potamiscus smithianus (China) serve as the second intermediate host (Seo, 1978; Blair et al., 1999). In adult specimens, the ventral sucker is characteristically small to be about a half the diameter of its oral sucker (Narain et al., 2010). It has a severely branched ovary and severely branched testes (Seo, 1978).

\subsubsection{Paragonimus kellicotti}

This lung fluke species was originally found in a cat and a dog in USA (Procop, 2009). Now this species is found in central and eastern parts of USA and adjacent areas of Canada (Procop, 2009). The definitive host other than 
humans is the skunk, red fox, coyote, mink, dog, pig, cat, and bobcat (Procop, 2009). An amphibian snail species, Pomatiopsis lapidaria, serves as the first intermediate host, and the crayfish, Cambarus spp., plays the role of the second intermediate host (Procop, 2009). The lobation of the ovary and testes is more complex that in $P$. westermani (Procop, 2009).

\subsubsection{Paragonimus mexicanus}

This lung fluke species was first found in opossums in Mexico (Miyazaki and Ishii, 1968). Now, it is known to distribute in Mexico, Peru, Ecuador, Costa Rica, Panama, and Guatemala (Blair et al., 1999). Natural definitive hosts other than humans include opossums, dogs, and cats (Blair et al., 1999). Freshwater snails, Aroapyrgus allei and Oncomelania spp., serve as the first intermediate host, and freshwater crabs, Hypolobocera spp., Pseudothelphusa spp., and Ptychophallus spp., play the role of the second intermediate host (Blair et al., 1999). Adult flukes of $P$. mexicanus are morphologically similar to $P$. kellicotti and $P$. skrjabini miyazakii (Yokogawa, 1969). Its characteristic morphologies include a somewhat larger oral sucker than the ventral sucker and a strongly lobed ovary and 2 testes (Blair et al., 1999).

\subsubsection{Paragonimus siamensis}

This lung fluke species was first described from cats infected with metacercariae from the freshwater crab Parathelphusa (Parathelphusa) germaini in Thailand (Miyazaki and Wykoff, 1965). Later, this lung fluke was also discovered in rats and mongooses in Sri Lanka ( Kannagara and Karunaratne, 1969). An adult specimen was recovered from a New Guinea native in 1926 and preserved in School of Public Health and Tropical Medicine, Australia; it was recently restudied and classified as $P$. siamensis (Wang et al., 2011). Filopaludina spp. freshwater snails are the first intermediate host (Yaemput et al., 1994), and freshwater crabs, including Ceylonthelphusa rugose, take the role of the second intermediate host (Blair et al., 1999).

\subsubsection{Paragonimus skrjabini}

This lung fluke species (= P. skrjabini) was first found from cats in China (Chen, 1962; Blair et al., 1999). It is now known to distribute in China, Thailand, Japan, Vietnam, and India (Miyazaki, 1991; Blair et al., 2005; Singh et al., 2006). Human infections were reported for the first time in Sichuan, China (Chen, 1962). Natural definitive hosts other than humans include monkeys, dogs, cats, weasels, mice, and rats (Blair et al., 1999). Freshwater snails, Assiminea lutea, Tricula spp., and Neotricula spp., serve as the first intermediate host, and freshwater crabs, Aprapotamon grahami, Isolapotamon spp., and Tenuilapotamon spp., take the role of the second intermediate host (Blair et al., 1999). One of the morphological characters is the profusely branched ovary and testes (Seo, 1978; Narain et al., 2010). The adult flukes typically have an elongated body just like P. skrjabini miyazakii (syn. P. miyazakii) (Blair et al., 2005). 1.2.1.8 Paragonimus skrjabini miyazakii

This lung fluke species was first described from dogs experimentally infected with the metacercariae from a freshwater crab Geothelphusa dehaani (syn. Potamon dehaani) in Japan (Kamo et al., 1961). Human infections were first identified in Kanto District of Japan (Yokogawa et al., 1974). Natural definitive hosts other than humans are dogs, cats, martens, weasels, and wild boars (Blair et al., 1999). Freshwater snails, Bythinella kubotai, Bythinella nipponica, and Oncomelania hupensis, serve as the first intermediate host, and freshwater crabs, Geothelphusa dehaani, play the role of the second intermediate host (Kamo et al., 1961). The adult flukes are somewhat elongated and morphologically close to $P$. kellicotti and $P$. skrjabini (Yokogawa, 1969; Blair et al., 2005). The severely branched ovary and testes are characteristic feature of this species (Miyazaki, 1991).

\subsubsection{Paragonimus uterobilateralis}

This lung fluke species was first described from mongooses in Cameroon (Narain et al., 2010), and now distributes in Cameroon, Nigeria, Liberia, Guinea, Ivory Coast, and Gabon (Blair et al., 1999). Human infection was first found in Nigeria, and then in all other countries mentioned above (Blair et al., 1999). Natural definitive hosts other than humans include dogs, cats, otters, mongoose, swamps, mongooses, shrews, and other rodents (Blair et al., 1999). The snail intermediate host has not been identified, and freshwater crabs Liberonautes spp. and Sudanonautes spp. serve as the second intermediate host (Blair et al., 1999). This species is morphologically similar to $P$. africanus but different in having similar-sized oral and ventral suckers (Miyazaki, 1991). It has a delicately branched ovary; however, it has moderately branched testes which are larger than the ovary (Blair et al., 1999). 


\subsubsection{Physical description (morphology)}

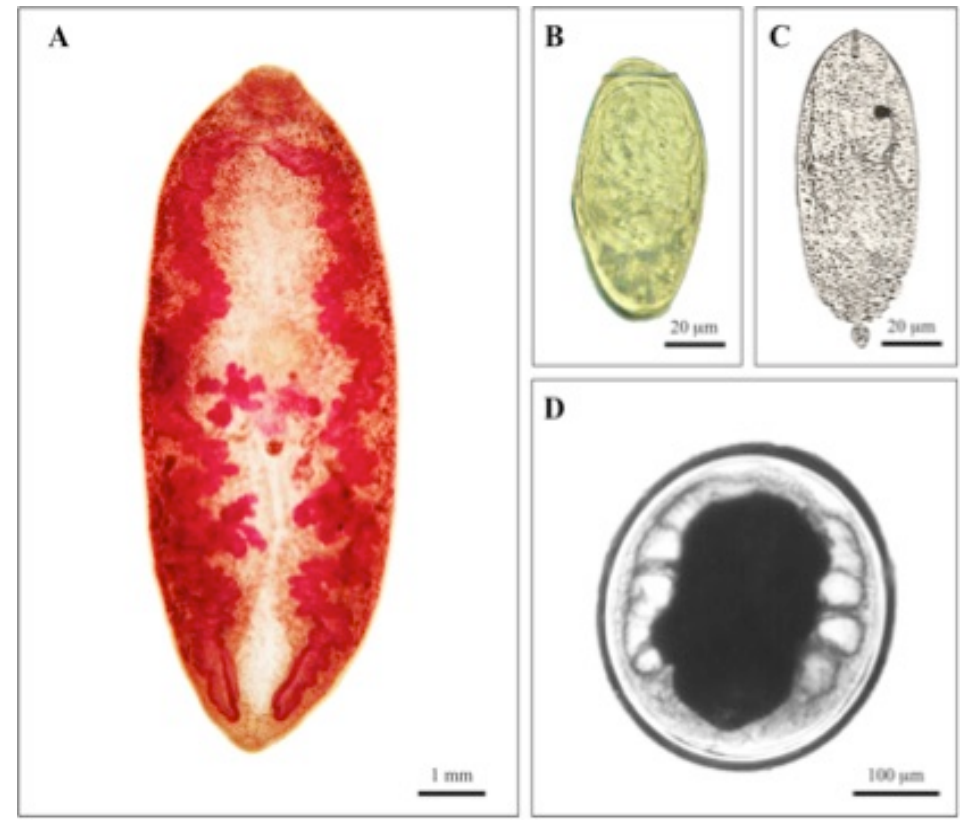

Figure 2. Morphology of an adult (A), egg (B), cercaria (C), and metacercaria (D) of Paragonimus westermani.

The adult flukes of Paragonimus spp. are large (7-12 mm long for P. westermani), plump, and coffee bean in their size and shape (Figure 2A) (Chai, 2013a). Their body surface is covered with tegumental spines. They have an oral sucker and a ventral sucker, and their relative size is a key for differentiation of the species (Sugiyama et al., 2013). Morphology of the ovary and testes, in particular, their branching patterns, is another character for the species determination (Sugiyama et al., 2013). The eggs are golden brown in color (Figure. 2B) and have an operculum at the anterior end and at times thickening at the abopercular end (Chai, 2013a). They are immature when laid, without a miracidium inside, and variable in size (70-90 $\mu \mathrm{m}$ long and 40-50 $\mu \mathrm{m}$ wide) depending on species (Figure 2B) (Sugiyama et al., 2013; Chai, 2013a). The cercariae have a small and short tail, thus called as microcercous cercariae. The cercariae have a large ventral sucker, and their exterior is equipped with tegumental spines (Figure 2C). The metacercariae are 280-450 $\mu \mathrm{m}$ in diameter depending on region of origin ( Sugiyama et al., 2013) and usually encyst in the tissues of crabs or crayfish (Figure 2D). They have 2 suckers and spined teguments. Recently, molecular characteristics were used to differentiate the species of Paragonimus, in addition to their morphologies ( Blair et al., 2005 ; Narain et al., 2010 ; Sugiyama et al., 2013; Doanh et al., 2013).

\subsection{Transmisson}

\subsubsection{Life cycle}

The eggs are excreted from the definitive host, including humans, via their sputum or feces and this begins the life cycle of Paragonimus spp. (Figure 3). When liberated in feces, the eggs are at an immature stage without miracidia inside. Miracidia develop within the eggs for 2-3 weeks, and then the eggs hatch in water. The miracidia are liberated to water and swim to infect a snail host (Chai, 2013a). They penetrate the tissues of the freshwater snail and localize in the hemocoel where each of the miracidium becomes a sporocyst (Blair et al., 1999). A sporocyst reproduces asexually into several rediae and then each redia reproduces into several daughter rediae (Chai, 2013a). A daughter redia may contain several cercariae each having a short tail (= microcercus cercaria) (Chai, 2013a). The cercariae swim in water and are infected to crustacean hosts such as the crab or crayfish (Chai, 2013a). Two modes of cercarial infection to crustacean hosts are suggested; one is the direct penetration of active cercariae into the crustacean host, and the other is ingestion of infected snails

by the crustacean host (Yokogawa et al., 1960; Yokogawa, 1965). In case of $P$. westermani, the main mode of cercarial transmission was suggested to be ingestion of an infected snail or of freed cercariae by the crab host (Yokogawa et al., 1960; Yokogawa, 1965). In other Paragonimus spp., cercariae that were liberated from the snail and swim in water may penetrate the crustacean host. When the metacercariae are ingested by (or infect) a definitive host, they excyst in the intestine, migrate to the pleural cavity where they mate, and then pair in worm cysts in the lungs (Blair et al., 1999). Worms paired in the lung can generally survive several years but they can also survive longer than 10 years in some cases (Yokogawa, 1965). 


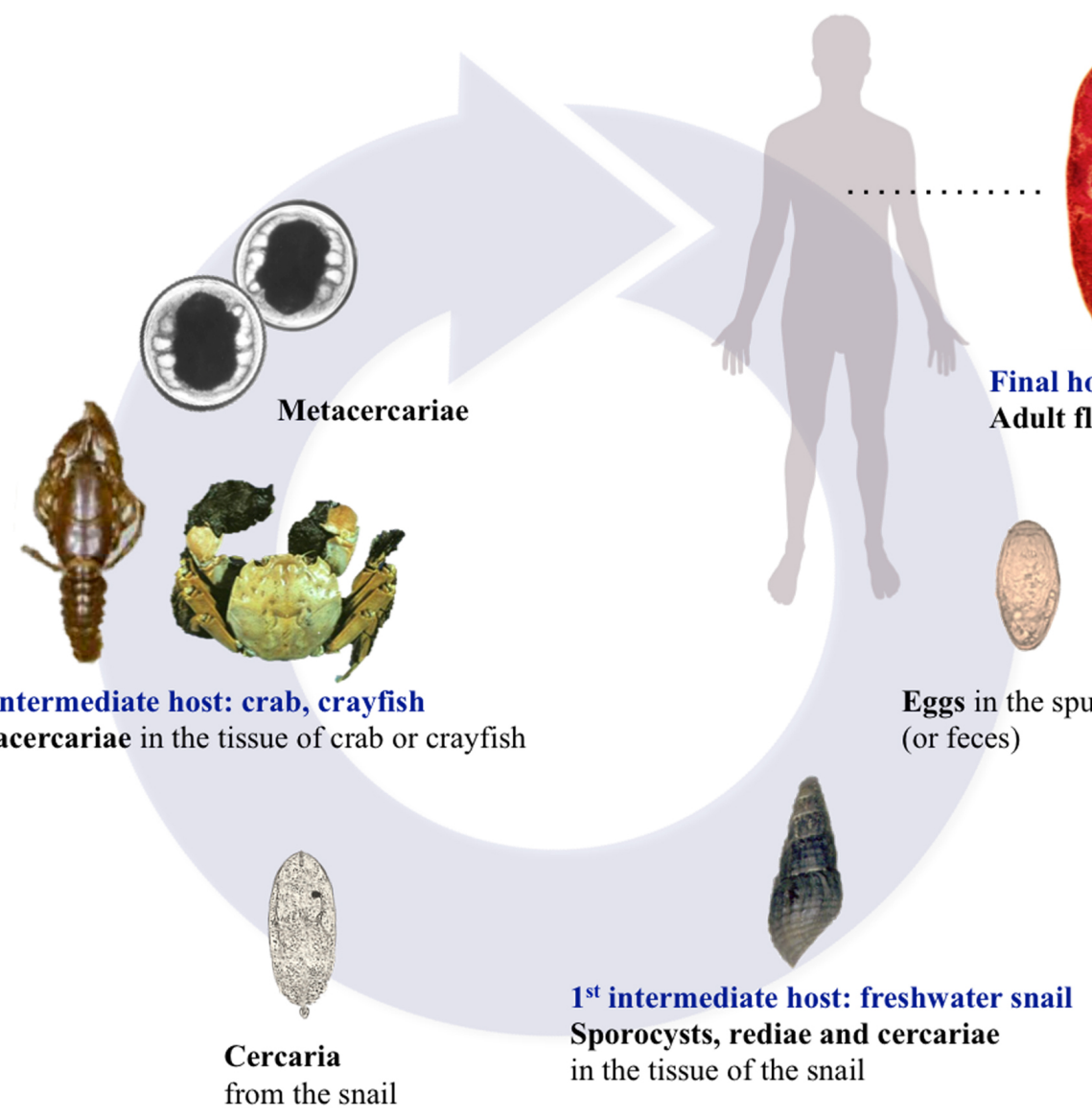

Figure 3. Common life cycle of Paragonimus spp. Human paragonimiasis occurs when raw or undercooked crab or crayfish are consumed. Some images of this figure are adapted from Google image.

\subsubsection{Routes of transmisson}

Paragonimiasis is a neglected disease that has received relatively little attention from public health authorities. There are various infection modes to infect with Paragonimus spp. One mode of infection is when live crabs are crushed during preparation the metacercariae may contaminate the utensils of the kitchen station. Accidental transfer of infective cysts can occur via food preparers who handle raw seafood and subsequently contaminate cooking utensils and other foods (Yokogawa, 1965). Food preparation techniques such as pickling and salting do not neutralize the causative agent. Another mode is that consumption of animals that feed on crustaceans can also transmit the parasite, such as eating raw boar meat. In some countries, people eat the crabs are soaked in wine for 3 to 5 minutes. It is an important risk factor for transmission of the disease (Yokogawa, 1965). Japanese group have suggested that infection with P. ohirai is possible among fishermen who crush infected crabs in their mouths before using them as bait (Kawashima and Miyahara, 1974). Some infection is undoubtedly also due to eating raw meat of paratenic hosts such as pigs (Miyazaki and Habe, 1976). Release of metacercariae from dead crustaceans and their survival in water used for drinking has been proposed that metacercariae can survive for days or weeks after removal (Yokogawa, 1965).

Human Paragonimus infection is usually caused by consumption of raw or improperly cooked (pickled) freshwater crabs or crayfish (Chai, 2013a). Famous dishes causing human paragonimiasis are known in Asian countries; they include 'drunken crab' in China, 'Kejang (= sauced crab)' in Korea, 'Oboro-kiro (= crab juice soup)' in Japan, 'Goong ten (= raw crayfish salad)' in Thailand, and 'Kinuolao (= raw crab)' in the Philippines (Kim, 1984; Nakamura-Uchiyama et al., 2002). Also in Africa, uncooked crab meat is the principal source of infection (Aka et al., 2008). In the US, frozen or pickled crabs available at markets are suspected to be the source of P. kellicotti infection (Procop, 2009). It is also known that 
Peruvians favor to eat raw crab with vegetables and lemon juice (Nakamura-Uchiyama et al., 2002), and Mexicans favor cerviche that contain uncooked crustacean meat (Procop, 2009). Freshwater crabs or crayfish juice were used in Korea and Japan for traditional treatment of febrile diseases, such as measles, asthma, and urticaria (Kim, 1984; NakamuraUchiyama et al., 2002). This kind of practice was an important mode of contracting paragonimiasis, especially in children. However, since recently, the disease incidence has been decreasing in Korea (Chai, 2004; Chai, 2007). Another important mode of infection in Japan is ingestion of raw or undercooked boar meat containing $m$. westermani metacercariae or juvenile worms (Miyazaki and Habe, 1975; Shibahara et al., 1992; Nakamura-Uchiyama et al., 2002). Wild boars, wild pigs, bears, and rats are paratenic hosts, and worms do not mature and stay in muscles and tissues. When they were eaten by humans, they could develop into adults (Chai, 2013a). Sometimes, paragonimiasis patients claim that they had never eaten freshwater crabs or crayfish (Chai, 2013a). In such cases, it can be considered that contamination of fingers with metacercariae might occur while cooking the crabs or crayfish (Nakamura-Uchiyama et al., 2002). Chopping board or other cooking utensils might also be contaminated with the metacercariae (Nakamura-Uchiyama et al., 2002).

\subsubsection{Reservoirs}

Lung flukes have a wide variety of natural definitive hosts which take the role for reservoir hosts. They include dogs, cats, pigs, leopards, tigers, foxes, wolves, opossums and minks in the South, Southeast, and East Asia, the Pacific Islands, north and sub-Saharan Africa, and North and South America (Blair et al., 1999; Procop, 2009). There are several kinds of paratenic hosts, for example, wild boars, bears, wild pigs, and rats; in these hosts worms do not mature to be adults but remain at a juvenile stage; they can survive in muscles for years and can be an important source of human infection (Miyazaki and Habe, 1975; Shibahara et al., 1992).

\subsubsection{Incubation period}

The incubation period, from infection to the onset of clinical symptoms, may vary from 2 to 16 weeks or even longer (CDC, 2010). However, a shorter incubation period of 2 to 15 days and appearance of early symptoms were also observed in $52 \%$ of cases in an outbreak of $P$. westermani infection in Harbin, China (Chung and Chao, 1962).

The prepatent period in the definitive host, from infection to beginning of oviposition, also varies according to the species of Paragonimus and its host, from 28 ( $P$. ohirai in rats) to 91 days (P. siamensis in cats) (Blair et al., 1999). The egg laying capacity of Paragonimus worms was reported to be 9,530-18,380 in EPD (eggs per day per worm) in dogs during days 64 to 151 post-infection (Yokogawa, 1965).

\subsubsection{Period of communicability}

Only the metacercarial stage of Paragonimus spp. is infective to humans. The metacercariae in the crab host were found to be infective to experimental dogs several months (for example, 6 months) after feeding them with the digestive glands of cercariae-infected snails (Yokogawa et al., 1960). It can be speculated that many of the metacercariae remain to be infective to the definitive host, including humans, throughout the life span of the crabs or crayfish (from a few to several years) (MSN, Korea, http://www.msn.com/ko-kr).

\subsubsection{Population susceptibility}

There has been no study regarding the susceptibility of different human population to Paragonimus spp. infection. However, some research group studied the susceptibility of different animals to Paragonimus spp. infection, for example, rats, dogs, and cats for Paragonimus iloktsuenensis infection (Lee et al., 1989b). The results revealed that at day 42 after infection, the recovery rate of adult worms was $53.3 \%$ from rats, $21.0 \%$ from dogs and $12.7 \%$ from cats (Lee et al., 1989b).

\subsection{Population and Individual Control Measures}

\subsubsection{Treatment options}

The drug of choice for treating paragonimiasis, including cerebral infections, is praziquantel (Chai, 2013b). Praziquantel is a broad-spectrum anthelmintic, which is safe and effective for treatment of various kinds of trematode and cestode infections (Rim et al., 1981; Lee and Chai, 1985; Chai et al., 1998; Chai, 2013b). The recommended dose for treatment of $P$. westermani infection is $25 \mathrm{mg} / \mathrm{kg}$, 3 times daily, for 2-3 days (Rim et al., 1981; Chai, 2013b). The same regimen of praziquantel can be used for treatment of infection with $P$. skrjabini (Sui et al., 1988), P. skjrabini miyazakii (Okamoto et al., 1993), $P$. heterotremus (De, 2004), P. kellicoti (Pachucki et al., 1984; Mariano et al., 1986), P. mexicanus (Saborio et al., 1995), $P$. africanus (Aka et al., 2008), and $P$. uterobilateralis (Udonsi, 1989). In severe P. westermani patients, for example, those with a high ELISA titer and/or multiple pulmonary lesions, a second set of praziquantel treatment may be needed (Oh et al., 2011). Allergic reactions may occur rarely, such as itching, febrile sensation, wheal, and painful swellings on the lip and eyelids (Kyung et al., 2011). However, such an allergic patient was successfully treated after desensitization to praziquantel (Kyung et al., 2011). Morphological changes of Paragonimus worms after praziquantel treatment were reported to include severe vacuolization of the tegument, subtegument, intestines, ovary, testes, and excretory bladder of the worms, and the vacuoles burst to form craters (Mehlhorn et al., 1983; Lee et al., 1987). Paragonimus worms in the worm cyst began to degenerate as early as day 3 after the treatment, and no recognizable worms remained after day 21 post-treatment (Lee et al., 1989c).

Triclabendazole is a new promising drug for treatment of 
pulmonary paragonimiasis and fascioliasis (Keiser et al., 2005). However, its efficacy on cerebrospinal paragonimiasis remains to be determined (Chai, 2013b). Triclabendazole was first used in experimental $P$. uterobilateralis infection in rats (Weber et al., 1988) and then in human paragonimiasis in Cameroon (Ripert et al., 1992). Subsequently, this drug was used to treat human $P$. mexicanus infection in Ecuador, and found to be highly safe, tolerable, and effective even with a single oral dose of $10 \mathrm{mg} / \mathrm{kg}$ body weight with a cure rate of $87.5 \%$ (Calvopiña et al., 1998). Higher doses, like $10 \mathrm{mg} / \mathrm{kg}$ twice daily, showed better effects, a $100 \%$ cure rate, therefore, this regimen became the recommended dose for treating paragonimiasis (Calvopiña et al., 1998). Triclabendazole was also proved to be useful for experimental P. skrjabini infection in rats, human patients infected with $P$. skrjabini and $P$. westermani infection in dogs (Liu et al., 1999; Gao et al., 2003). However, in Korea, a human patient of $P$. westermani infection was not cured by a $10 \mathrm{mg} / \mathrm{kg}$ single dose of triclabendazole treatment (Kyung et al., 2011). Its efficacy on $P$. westermani infection should be clarified (Chai, 2013b).

\subsubsection{Vaccine}

No applicable preventive and therapeutic vaccines against paragonimiasis have yet been developed. Recently, the study about transcriptome, proteome, and immunolome of adult $P$. kellicotti provide powerful information to develop improved diagnostic tests. However, these results may lead to the development of the effective future vaccine against Paragonimus spp. infection (McNulty et al., 2014). Such integrated approaches may be useful for development of vaccines in the future (McNulty et al., 2014).

\subsubsection{Hygiene measures}

There are 2 principal points regarding the control strategy of water- or foodborne trematode infections (Abdussalam et al., 1995). One of them is prevention of contamination of water or food with metacercariae of Paragonimus as infective stages, and another is inactivation of metacercariae in the contaminated water or infected food.

Prevention of contamination of the crab and crayfish depends on environmental control of surface waters through the control or elimination of freshwater snails as first intermediate host (Abdussalam et al., 1995). However, such hygiene measures present many difficulties for monitoring and control in large scale of surface waters (rivers, lakes) and may be impracticable (Abdussalam et al., 1995). Improvement of aquaculture may be possible with the cooperation and participation of the people (World Health Organization, 1995).

\subsection{Environmental Occurrence and Persistence}

\subsection{Detection Methods}

\subsubsection{Conventional detection methods}

The conventional methods to detect human Paragonimus infections consist of microscopic examinations of the sputum or fecal samples for detection of eggs, chest $\mathrm{X}$-ray to observe the lung lesions, and intradermal test, indirect hemagglutination test, enzyme-linked immunosorbent assay (ELISA), and rapid test to detect antibodies (Lee et al., 2003; Sugiyama et al., 2013). The cercariae and metacercariae of Paragonimus worm can be detected in intermediate hosts and various types of contaminated water or food sources in the environment.

The detection technique for intermediate hosts (freshwater crabs and crayfish) is as follows (World Health Organization, 1995). First, for check the infectious status of metacercariae, dissect and then compress each part of the crab or crayfish between 2 glass slides, and examine a slide under the stereomicroscope at low magnifications to determine the presence and number of metacercariae (World Health Organization, 1995). Second, to determine only the presence of infection, crush the whole body of crab or crayfish in a mortar. Discard the crushed crustacean shell and tissues and isolate the metacercariae from the saline washes by repeated sedimentation and decanting of the supernatant. Collect the isolated metacercariae on a watch glass, and count them under a stereomicroscope (World Health Organization, 1995).

\subsubsection{Molecular detection methods}

It is difficult to identify the causative species of Paragonimus spp. based only on the morphological characteristics of specimens. In the case, molecular-based detection methods including PCR and DNA sequencing is useful to identify the specimens specifically (Chang et al., 2000). Other potential methods including restriction fragment-length polymorphism (RFLP) analysis, PCR-RFLP, multiplex PCR, random amplified polymorphic DNA (RAPD) and DNA hybridization, have also been applied for the identification and infectious status of Paragonimus at various life cycle stages or indistinguishable morphological characteristics (Narain et al., 2010; Sugiyama et al., 2013).

\subsection{Data on Occurrence in the Environment}

The snail as intermediate host of $P$. westermani is most frequently found in swift-moving mountain streams which may be at some distance from human habitations; such streams are also the preferred habitats for the freshwater crabs or crayfish which serve as the second intermediate hosts (Yokogawa et al., 1960; Yokogawa, 1965).

\subsubsection{Excreta in environment}

The presence of pathogenic eggs of lung flukes in the feces of the definitive host, including humans, as well as in the wastewater and fecal sludge in the environment, is very harmful. However, there is no specific information on the occurrence of Paragonimus spp. in various types of polluted water in the environment. Based on information from those of other helminths, it is expected that the average number 
of eggs of Paragonimus spp. in fresh fecal sample (whole day sample) will be approximately 102-104 (Williams and Overbo, 2015).

\subsubsection{Pit latrines and groundwater}

Several research teams measured the microbiological contamination of groundwater and pit latrines, however, there is no studies examined the Paragonimus spp. contamination (Graham and Polizzotto, 2013; Lewis et al., 1982).

\subsubsection{Sewage}

One of the potential hazards in sewage is the presence of Paragonimus eggs excreted in feces from the definitive host. However, there are no quantitative data on these kinds of eggs in sewage. Although some research group studied the average concentrations of various pathogens present in human excreta and wastewater (Lucena et al., 2003), they did not analyze the presence of parasites, including Paragonimus spp. Therefore, surveys to analyze the concentrations of parasitic pathogens may still be needed in various environments such as ground water, pit latrines, and sewage.

\subsection{Persistence Data}

\subsubsection{Persistence of eggs}

No recent data are available regarding the persistence of Paragonimus eggs in sewage. It was previously reported that the eggs were quickly killed by freezing but survived for long periods at $4^{\circ} \mathrm{C}$; they did not develop at temperatures above $35^{\circ} \mathrm{C}$ and were rapidly killed by desiccation (Yokogawa et al., 1960). Paragonimus eggs in a biogas plant in China survived for 13 days (Hou et al., 1959). The typical minimum time from excretion to infectivity (latency) of Paragonimus spp. was about 4 months and the estimated maximum life of infective stage at $20-30^{\circ} \mathrm{C}$ (persistence) was same as duration of the life of intermediate hosts such as crabs or crayfish (Feachem et al., 1983).

\subsubsection{Persistence of metacercariae in the environment}

A research group observed the survivability of Paragonimus metacercariae under different conditions such as temperature, liquids (Fan et al., 1990). The metacercariae of $P$. westermani from fresh crabs were kept into 5 different types of liquids at different temperatures to determine the survival rate of each group. Results revealed that the metacercariae in Ringer's solution and normal saline survived longer than in other liquids, and that their survival periods were 84.42 and 78.93 days, respectively. The average survival period in tap water, dechlorinated water and well water were 48.2, 52.14 and 56.21 days, respectively. The results suggest strongly that Paragonimus metacercariae can survive for 2-3 months in normal various drinking water under low temperature (Fan et al., 1990).

In the tissues of dead crabs, the encysted metacercariae of $P$. westermani lived for a week in winter, and the cysts freed in water remained viable for 2-3 weeks (Yokogawa et al., 1960). The encysted metacercariae kept at $4^{\circ} \mathrm{C}$ or in vitro were alive for at least 21 days (Kim et al., 2017b) or over 200 days (Yokogawa et al., 1960), respectively. The metacercariae kept in frozen freshwater crabs at $-20^{\circ} \mathrm{C}$ were completely killed before day 2 after the keeping (Kim et al., 2017b). Whereas heating to $55^{\circ} \mathrm{C}$ for $10 \mathrm{~min}$ could kill all the metacercariae, heating to $45^{\circ} \mathrm{C}$ for $37 \mathrm{~min}$ allowed them to remain viable (Yokogawa et al., 1960). If the crabs are cooked until the muscles turned white, all of the $P$. westermani metacercariae were killed (Yokogawa et al., 1960). Similarly, in the viscera of dead crayfish, the metacercariae of $P$. kellicotti lived for 5 days at $12-21^{\circ} \mathrm{oC}$, and at these temperature the cysts freed in water remained viable for 10 days in winter (Yokogawa et al., 1960). When small pieces of infected crayfish meat were placed in a mixture of soy sauce, vinegar, salt, and sugar for 3 hours, the metacercariae were killed.

\subsection{Reductions by Sanitation Management}

The environmental water source should be protected from pollution with sewage, other wastes, and untreated human and animal excreta. A WHO Scientific Group on Health Guidelines for the Use of Wastewater in Agriculture and Aquaculture emphasized that in many developing countries the main risks of wastewater usage were due to helminthic infections (World Health Organization, 1989). However, the recommendations of this Scientific Group for safe use of wastewater in aquaculture for the control of foodborne trematodes remain to be tested (Abdussalam et al., 1995). The intersectoral collaboration between the various governmental sectors including department of agriculture, aquaculture, public health, and education or collaborative activity between food safety experts and parasitologists may decrease in the disease incidence (Abdussalam et al., 1995).

Previous results have shown the methods for sanitation management to reduce the prevalence of diarrheal disease induced by infection of helminths including Paragonimus spp. (Esrey et al., 1991; Fewtrell et al., 2005; Ziegelbauer et al., 2012).

\subsection{Sanitation technology}

No data were found on removal of the eggs by sewage treatment processes, thus this is a data gap.

\subsection{Disinfection}

A number of methods such as temperature, solution, irradiation and salting are currently applied in water and food processing. Such processing conditions for the inhibition of the water or food-borne Paragonimus spp. infectivity have been showed the list in Table 3. 
Table 3. Processing conditions under which inhibition of infectivity of lung fluke metacercariae has been observed.

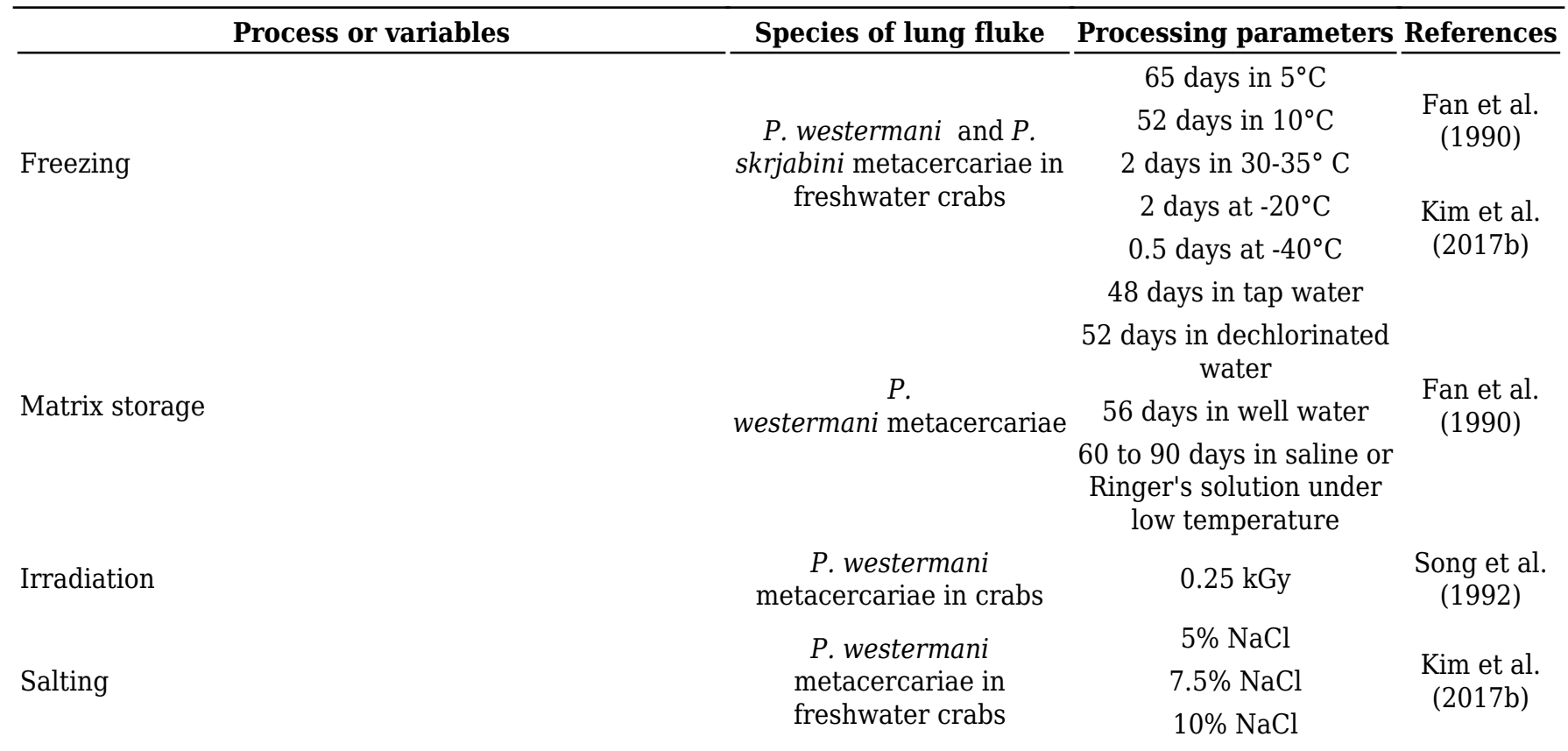

\subsubsection{Temperature}

The survival of the metacercaria was closely related to the temperature regardless of the type of liquid. The survival periods for metacercaria in $5^{\circ} \mathrm{C}, 10^{\circ} \mathrm{C}, 30-35^{\circ} \mathrm{C}$ were 64.38 and 51.74 days, just 1.35 days respectively (Fan et al., 1990). The results of this experiment suggested that the metacercariae of Paragonimus can maintain the infectivity at low temperature during winter season (Fan et al., 1990). However, all metacercariae of Paragonimus in the freshwater crabs were inactivated after freezing for 48 $\mathrm{hr}$ at $-20^{\circ} \mathrm{C}$ and after freezing for $12 \mathrm{hr}$ at $-40^{\circ} \mathrm{C}$ (Kim et al., 2017b).

\subsubsection{Irradiation}

A study observed that the irradiation affects the infectivity of Paragonimus westermani metacercariae in the cat and mice infected with metacercariae under 60Co as source of radiation (Song et al., 1992). Adult cats and albino mice were infected with the metacercariae irradiated at various doses (0.05-4.0 kGy). After 30 days in mice, antimetacercaria antibody was tested with sera from infected mice by enzyme linked immunosorbent assay (ELISA) and 90 days in cat, they recovered the lung fluke from infected cats (Song et al., 1992). No young or adult worms were recovered from mice when the metacercariae were irradiated at a dose of $2.5 \mathrm{kGy}$. Thus, at least $2.5 \mathrm{kGy}$ or higher irradiation is regarded as an effective dose to control infectivity of Paragonimus metacercariae from host freshwater crabs (Song et al., 1992).

\subsubsection{Salting}

There are a variety of recipes for making the freshwater crab food. When the metacercariae do not kill in marinated or salting condition, ingestion of such crabs is a main route of infection in Korea, China, Taiwan, and the Philippines (Fan and Khaw, 1964; Micozzi and Ongchangco, 1980; Kim et al., 2017b). After marinating of freshwater crabs infected with metacerariae of Paragonimus in soy sauce for 32 days, the survival rate of the metacercariae of Paragonimus was $50 \%, 33.3 \%, 31.3 \%$ in $5 \% 7.5 \%, 10.0 \% \mathrm{NaCl}$ soy sauce, respectively (Kim et al., 2017b). All the metacercariae of Paragonimus were inactivated in all experimental groups after marinating for 64 days (Kim et al., 2017b). Therefore, at least $5.0 \% \mathrm{NaCl}$ for 64 days can inactivate the metacercariae of Paragonimus (Kim et al., 2017b).

\subsection{Conclusion and Perspectives}

Nine species of Paragonimus are currently known to infect humans around the world, which include $P$. westermani (most widespread species), $P$. africanus, $P$. heterotremus, $P$. kellicotti, $P$. mexicanus, $P$. siamensis, $P$. skrjabini, $P$. skrjabini miyazakii, and $P$. uterobilateralis. They are distributed mainly in Asia, Africa, and North and South America. They can cause pulmonary (in the lungs) as well as extrapulmonary diseases (in the abdominal organs, brain, spinal cord, and cutaneous tissues). The diagnosis of pulmonary or extrapulmonary infections can be done by sputum examination for eggs and/or serological techniques, such as latex agglutination and ELISA, to detect antibodies. Praziquantel or triclabendazole can be used for successful treatment of paragonimiasis patients. Avoidance of consuming raw or improperly cooked crabs, crayfish, and boar meat is the most important prevention strategy.

The global burden so far reported may be underestimates. In some areas, this disease is reported to be decreasing but in other areas it is emerging or 
reemerging. There may be not a few hidden endemic areas. To uncover the real global situation of this disease, more efficient and feasible diagnostic techniques, including immunological and molecular techniques, should be introduced. In addition, more effective and efficient preventive measures should be developed, for example, heating, freezing, as well as irradiation and proper salting of freshwater crab and crayfish dishes. 


\section{References}

Abdussalam, M., Kaferstein, F.K. and Mott, K.E. (1995). Food safety measures for the control of foodborne trematode infections. Food Control. 6, pp. 71-79.

Aka, N.A., Adoubryn, K., Rondelaud, D. and Dreyfuss, G. (2008). Human paragonimiasis in Africa. Annals of African Medicine. 7, pp. 153-162.

Blair, D., Chang, Z., Chen, M., Cui, A., Wu, B., Agatsuma, T. et al. (2005). Paragonimus skrjabini Chen, 1959 (Digenea: Paragonimidae) and related species in eastern Asia: a combined molecular and morphological approach to identification and taxonomy. Systematic Parasitology. 60, pp. 1-21.

Blair, D., Xu, Z.B. and Agatsuma, T. (1999). Paragonimiasis and the genus Paragonimus. Advances in Parasitology. 42, pp. 113-222.

Boland, J.M., Vaszar, L.T., Jones, J.L., Mathison, B.A., Rovzar, M.A., Colby, T.V. et al. (2011). Pleuropulmonary infection by Paragonimus westermani in the United States: a rare cause of eosinophilic pneumonia after ingestion of live crabs. The American Journal of Surgical Pathology. 35, pp. 707-713.

Brenes, R.R., Rodriguez-Ortiz, B., G Solano, V., Obando, EM.Ocamp and Sotela, PJ.Ruiz (1982). Cerebral hemorrhagic lesions produced by Paragonimus mexicanus: report of three cases in Costa Rica. The American Journal of Tropical Medicine and Hygiene. 31, pp. 522-526.

Calvopiña, M., Guderian, R.H., Paredes, W., Chico, M. and Cooper, P.J. (1998). Treatment of human pulmonary paragonimiasis with triclabendazole: Clinical tolerance and drug efficacy. Transactions of the Royal Society of Tropical Medicine and Hygiene. 92, pp. 566-569.

CDC (2010). Human paragonimiasis after eating raw or undercooked crayfish - Missouri, July 2006-September 2010. Morbidity and Mortality Weekly Report. 59, pp. 1573-1576.

CDC (1999). Paragonimiasis. Division of Parasitic Diseases, National Center for Infectious Diseases, Centers for Disease Control and Prevention. Atlanta, GA.

Chai, J.Y. (2013). Praziquantel treatment in trematode and cestode infections: an update. Infection and Chemotherapy. 45, pp. 32-43.

Chai, J.Y. (2007). Transition of parasitic diseases in Korea. Infection and Chemotherapy. 39, pp. S156-S172.

Chai, J.Y. (2004). Food-borne parasitic infections. Journal of the Korean Medical Association. 47, pp. $496-507$.

Chai, J.Y. (2013). Paragonimiasis. roparasitology and Tropical Neurology. (Garcia, H., Tanowitz, H. and Del Brutto, O.D., ed.). Elsevier. Amsterdam, Netherlands. pp. 283-296.

Chai, J.Y., Hong, S.J., Hong, S.T. and Lee, S.H. (1998). Treatment of liver, lung, and intestinal fluke infections with praziquantel in Korea. Proceedings in 5th Asian-Pacific Congress on Zoonotic Parasitology. pp. 18-27.

Chai, J.Y., Hong, S.T., Choi, M.H., Shin, E.H., Bae, Y.M., Hong, S.J. et al. (2011). Clinical Parasitology (Textbook). Seoul National University. Seoul, Korea. pp. 349-356.

Chen, H.T. (1962). The etiologic agent of human paragonimiasis in China. Chinese Journal of Integrative Medicine. 81, pp. 345-353.

Choi, D.W. (1990). Paragonimus and paragonimiasis in Korea. Korean Journal of Parasitology. 28, pp. 79-102.

Choo, J.D., Suh, B.S., Lee, H.S., Lee, J.S., Song, C.J., Shin, D.W. et al. (2003). Chronic cerebral paragonimiasis combined 
with aneurysmal subarachnoid hemorrhage. The American Journal of Tropical Medicine and Hygiene. 69, pp. 466-469.

Chung, H.L. and Taso, W.C. (1962). Paragonimus westermani (Szechuan variety) and a new species of lung flukeParagonimus szechuanensis. II. Studies on clinical aspects of paragonimasis szechuanensis-a new clinical entity. Chinese Journal of Integrative Medicine. 81, pp. 419-434.

De, N.V. (2004). Epidemiology, pathology and treatment of paragonimiasis in Vietnam. Southeast Asian Journal of Tropical Medicine and Public Health. 35, pp. 331-336.

Doanh, P.N., Horii, Y. and Nawa, Y. (2013). Paragonimus and paragonimiasis in Vietnam: an update. Korean Journal of Parasitology. 51, pp. 621-627.

Esrey, J., Potash, J.B., Roberts, L. and Shiff, C. (1991). Effects of improved water supply and sanitation on ascariasis, diarrhoea, dracunculiasis, hookworm infection, schistosomiasis, and trachoma. Bulletin of the World Health Organization. 69, pp. 609-621.

Fürst, T., Keiser, J. and Utzinger, J. (2012). Global burden of human food-borne trematodiasis: a systematic review and meta-analysis. The Lancet Infectious Diseases. 12, pp. 210-221.

Fan, P.C. and Khaw, O.K. (1964). Relationship of food habits to human infection with Paragonimus westermani. I. Experimental infection with metacercariae of Paragonimus westermani of 'drunken crabs', Eriocheir japonicus in cats. Journal of the Chinese Medical Association. 11, pp. 262-276.

Fan, P.C., King, D.C. and Lee, J.H. (1990). Prevalence of metacercariae of Paragonimus westermani in Cambaroides similis on Kanghwa Island, Korea, with special reference to survival and infectivity of metacercariae kept at low temperature for a long period. Parasitology and Institute of Tropical Medicine, Yonsei University. 21, pp. 9-17.

Feachem, R.G., Breadley, D.J., Garelick, H. and Mara, D.D. (1983). Sanitation and Disease - Health Aspects of Excreta and Wastewter Management. John Wiley and Sons. Chichester, UK.

Fewtrell, L., Kaufmann, R., Kay, D., Enanoria, W., Haller, L. and Colford, J. (2005). Water, sanitation, and hygiene interventions to reduce diarrhoea in less developed countries: a systematic review and meta-analysis. Lancet. 5, pp. 42-52.

Fried, B. and Abruzzi, A. (2010). Food-borne trematode infections of humans in the United States of America. Parasitology Research. 106, pp. 1263-1280.

Gao, J., Liu, Y., Wang, X. and Hu, P. (2003). Triclabendazole in the treatment of paragonimiasis skrjabini. Chinese Medical Journal. 116, pp. 1683-1686.

Graham, J.P. and Polizzotto, M.L. (2013). Pit latrines and their impacts on groundwater quality: a systematic review. Environmental Health Perspectives. 121, pp. 521-530.

Havelaar, A.H., Kirk, M.D., Torgerson, P.R., Gibb, H.J., Hald, T., Lake, R.J. et al. (2015). World Health Organization Foodborne Disease Burden Epidemiology Reference Group. World Health Organization Global Estimates and Regional Comparisons of the Burden of Foodborne Disease in 2010. PLoS Medicine. 12, pp. e1001923.

Hayashi, K., Ohtsuki, Y., Ikehara, I., Akagi, T., Murakami, M., Date, I. et al. (1986). Primary rhabdomyosarcoma combined with chronic paragonimiasis in the cerebrum: a necropsy case and review of the literature. Acta Neuropathologica. 72, pp. 170-177.

Hernández-Chea, R., Jiménez-Rocha, A.E., Castro, R., Blair, D. and Dolz, G. (2017). Morphological and molecular characterization of the metacercaria of Paragonimus caliensis, as a separate species from P. mexicanus in Costa Rica. International Journal for Parasitology. 66, pp. 126-133.

Hong, S.T., Lee, S.H., Chi, J.G., Jin, Y.S., Kim, C.S. and Chang, Y.S. (1982). A case of systemic paragonimiasis with ovarian involvement. Korean Journal of Parasitology. 20, pp. 53-59.

Hou, T.C., Chung, H.L., Ho, L.Y. and Weng, H.C. (1959). Achievements in the fight against parasitic diseases in New China. 
Chinese Medical Journal. 79, pp. 493-520.

Im, J.G., Kong, Y., Shin, Y.M., Yang, S.O., Song, J.G., Han, M.C. et al. (1993). Pulmonary paragonimiasis: clinical and experimental studies. Radiographics. 13, pp. 575-586.

Jiang, Y., Ge, L., You, Y. and Shen, Z. (2015). The diagnosis of cutaneous paragonimiasis after the external migration of the parasite from a punch biopsy site. JAAD Case Reports. 1, pp. 239-240.

Kamo, H., Nishida, H., Hatsushika, R. and Tomimura, T. (1961). On the occurrence of a new lung fluke, Paragonimus miyazakii n. sp. in Japan (Trematoda: Troglotrematidae). Yonago Acta Medica. 5, pp. 43-52.

Kannagara, D.W.W. and Karunaratne, G.M.S. (1969). Paragonimus siamensis: the fourth lung fluke reported from Ceylon. Ceylon Journal of Medical Science. 18, pp. 61-65.

Kawashima, K. and Miyahara, M. (1974). Studies on Paragonimus ohirai Miyazaki, 1939, found in Is. Yakushima, Kagoshima Precture, Japan. Japanese Journal of Parasitology. 23, pp. 369-375.

Keiser, J., Engels, D., Büscher, G. and Utzinger, J. (2005). Triclabendazole for the treatment of fascioliasis and paragonimiasis. Expert Opinion on Investigational Drugs. 14, pp. 1512-1526.

Keiser, J. and Utzinger, J. (2005). Emerging foodborne trematodiasis. Emerging Infectious Diseases. 11, pp. 1504-1507.

Kim, D.C. (1984). Paragonimus westermani: life cycle, intermediate hosts, transmission to man and geographical distribution in Korea. Arzneimittel Forschung - Drug Research. 34, pp. 1180-1183.

Kim, M.J., Kim, S.H., Lee, S.O., Choi, S.H., Kim, Y.S., Woo, J.H. et al. (2017). A case of ectopic peritoneal paragonimiasis mimicking diverticulitis or abdominal abscess. Korean Journal of Parasitology. 55, pp. 313-317.

Kim, M.K., Cho, B.M., Yoon, D.Y. and Nam, E.S. (2011). Imaging features of intradural spinal paragonimiasis: a case report. British Journal of Radiology. 84, pp. e72-e74.

Kim, T.I., Oh, S.R., Dai, F., Yang, H.J., Ha, S.D. and Hong, S.J. (2017). Inactivation of Paragonimus westermani metacercariae in soy sauce-marinated and frozen freshwater crabs. Parasitology Research. 116, pp. 1003-1006.

Kim, T.W., Lim, C.S., Park, S.M., Chi, M.P., Kim, J.O. and Kim, J.C. (2000). A case of cerebral paragonimiasis combined with a meningioma. Journal of Korean Neurosurgical Society. 29, pp. 800-804.

Koh, E.J., Kim, S.K., Wang, K.C., Chai, J.Y., Chong, S., Park, S.H. et al. (2012). The return of an old worm: cerebral paragonimiasis presenting with intracerebral hemorrhage. Journal of Korean Medical Science. 27, pp. 1428-1432.

Kusner, D.R. and King, C.H. (1993). Cerebral paragonimiasis. Seminars in Pediatric Neurology. 13, pp. $201-208$.

Kyung, S.Y., Cho, Y.K., Kim, Y.J., Park, J.W., Jeong, S.H., Lee, J.I. et al. (2011). A paragonimiasis patient with allergic reaction to praziquantel and resistant to triclabendazole: successful treatment after desensitization to praziquantel. Korean Journal of Parasitology. 49, pp. 73-77.

Lane, M.A., Barsanti, M.C., Santos, C.A., Yeung, M., Lubner, S.J. and Weil, G.J. (2009). Human paragonimiasis in North America following ingestion of raw crayfish. Clinical Infectious Diseases. 49, pp. e55-e61.

Lee, S.H. and Chai, J.Y. (1985). Praziquantel in the treatment of trematode and cestode infections. Journal of the Korean Society for Chemotherapy. 3, pp. 95-118.

Lee, S.H., Kim, M.N., Back, B.Y., Chai, J.Y., Kim, T.H. and Hwang, Y.S. (2003). Analysis of parasite-specific antibody positive patients for Clonorchis sinensis, Paragonimus westermani, cysticercus and sparganum using ELISA. The Korean Journal of Laboratory Medicine. 23, pp. 126-131.

Lee, S.H., Kim, S.Y., Han, Y.C., Lee, Y.S., Hong, S.T., Sohn, W.M. et al. (1989). Effect of praziquantel treatment on pulmonary lesions of rats infected with Paragonimus iloktsuenensis. Korean Journal of Parasitology. 27, pp. 119-130. 
Lee, S.H., Koo, K.H., Chai, J.Y., Hong, S.T. and Sohn, W.M. (1989). Experimental infection of Paragonimus iloktsuenensis to albino rats, dogs and cats. Korean Journal of Parasitology. 27, pp. 197-202.

Lee, S.H., Park, H.J., Hong, S.J., Chai, J.Y. and Hong, S.T. (1987). In vitro effect of praziquantel on Paragonimus westermani by light and scanning electron microscopic observation. Korean Journal of Parasitology. 25, pp. 24-36.

Lee, S.H., Sung, S.H. and Chai, J.Y. (1989). Immunohistochemical study on the antigenicity of body compartments of Paragonimus westermani. Korean Journal of Parasitology. 27, pp. 109-117.

Lewis, W.J., Foster, S.S.D. and Drasar, B.S. (1982). The risk of groundwater pollution by on-site sanitation in developing countries: a literature review. IRCWD Report No. 01/82. International Reference Centre for Waste Disposal (IRCWD). Duebendorf, Switzerland.

Liu, Y.H., Gao, J.S., Wang, X.G., Yu, D. and Su, Q. (1999). Experimental observation of effects of triclabendazole on Paragonimus westermani infection in dogs. Chinese Medical Journal. 112, pp. 345-348.

Lucena, F., Méndez, X., Morón, A., Calderón, E., Campos, C., Guerrero, A. et al. (2003). Occurrence and densities of bacteriophages proposed as indicators and bacterial indicators in river waters from Europe and South America. Journal of Applied Microbiology. 94, pp. 808-815.

Mariano, E.G., Borja, S.B. and Vruno, M.J. (1986). A human infection with Paragonimus kellicotti (lung fluke) in the Unites States. American Journal of Clinical Pathology. 86, pp. 685-687.

McNulty, S.N., Fischer, P.U., Townsend, R.R., Curtis, K.C., Weil, G.J. and Mitreva, M. (2014). Systems biology studies of adult Paragonimus lung flukes facilitate the identification of immunodominant parasite antigens. PLOS Neglected Tropical Diseases. 8, pp. e3242.

Mehlhorn, H., Kojima, S., Rim, H.J., Ruenwongsa, P., Andrews, P., Thomas, H. et al. (1983). Ultrastructural investigations on the effects of praziquantel on human trematodes from Asia: Clonorchis sinensis, Metagonimus yokogawai, Opisthorchis viverrini, Paragonimus westermani and Schistosoma japonicum. Arzneim Forsch/Drug Res. 33, pp. 91-98.

Meyers, W.M. and Neafie, R.N. (1976). Chapter 3. Paragonimiasis. Pathology of Tropical and Extraordinary Diseases. 2nd ed. (Binford, C.H. and Conner, D.H., ed.). Armed Forces Institute of Pathology. Washington, DC.

Micozzi, M.S. and Ongchangco, M.N. (1980). A case of pulmonary paragonimiasis in Mindanao, Philippines. The Southeast Asian Journal of Tropical Medicine and Public Health. 11, pp. 67-69.

Miyazaki, I. (1991). An Illustrated Book of Helminthic Zoonoses. International Medical Foundation of Japan. pp. 76-146.

Miyazaki, I. and Habe, S. (1976). A newly recognized mode of human infection with lung flukes, Paragonimus westermani (Kerbert, 1878). Journal of Parasitology. 48, pp. 23-24.

Miyazaki, I. and Habe, S. (1975). A newly recognized mode of infection with the lung fluke. Risho to kenkyo. 52, pp. $3606=3609$.

Miyazaki, I. and Ishii, Y. (1968). Studies on the Mexican lung flukes, with special reference to a description of Paragonimus mexicanus spp. nov. (Trematoda: Troglotrematidae). Japanese Journal of Parasitology. 17, pp. 445-453.

Miyazaki, I. and Vajrasthira, S. (1967). Occurrence of the lung fluke Paragonimus heterotremus Chen et Hsia, 1964, in Thailand. Journal of Parasitology. 53, pp. 207.

Miyazaki, I. and Wykoff, D.E. (1965). On a new lung fluke Paragonimus siamensis n. sp. found in Thailand (Trematoda: Troglotrematidae). Japanese Journal of Parasitology. 14, pp. 251-257.

Nagayasu, E., Yoshida, A., Hombu, A., Horii, Y. and Maruyama, H. (2015). Paragonimiasis in Japan: a twelve-year retrospective case review (2001-2012). Internal Medicine. 54, pp. 179-186.

Nakamura-Uchiyama, F., Mukae, H. and Nawa, Y. (2002). Paragonimiasis: a Japanese perspective. Clinics in Chest 
Medicine. 23, pp. 409-420.

Nakamura-Uchiyama, F., Onah, D.N. and Nawa, Y. (2001). Clinical features of paragonimiasis cases recently found in Japan: parasite-specific immunoglobulin M and G antibody classes. Clinical Infectious Diseases. 32, pp. e171-e175.

Narain, K., Agatsuma, T. and Blair, D. (2010). Paragonimus. Molecular Detection of Foodborne Pathogens. (Liu, D., ed.). CRC Press, Taylor \&amp; Francis Group, LLC. Boca Raton, FL. pp. 827-837.

Oh, I.J., Kim, Y.I., Chi, S.Y., Ban, H.J., Kwon, Y.S., Kim, K.S. et al. (2011). Can pleuropulmonary paragonimiasis be cured by only the 1st set of chemotherapy? Treatment outcome and clinical features of recently developed pleuropulmonary paragonimiasis. Internal Medicine. 50, pp. 1365-1370.

Oh, S.J. (1969). Cerebral and spinal pragonimiasis. A histopathological study. J Neurol Sci. 9, pp. 205-236.

Oh, S.J. (1968). Roentgen findings in cerebral paragonimiasis. Radiology. 90, pp. 292-299.

Oh, S.J. (1968). Spinal paragonimiasis. Journal of the Neurological Sciences. 6, pp. 125-140.

Oh, S.J. (1968). Paragonimus meningitis. Journal of the Neurological Sciences. 6, pp. 419-433.

Okamoto, M., Miyake, Y., Shouji, S.I., Fujikawa, T., Tameda, Z. and Nawa, Y. (1993). A case of severe paragonimiasis miyazakii with lung and skin lesions showing massive egg production in sputum and faeces. Japanese Journal of Parasitology. 42, pp. 429-433.

Ooi, H., Chang, S., Huang, C., Kawakami, Y. and Uchida, A. (2000). Survey of Spirometra erinaceieuropaei in frogs in Taiwan and its experimental infection in cats. Journal of Helminthology. 74, pp. 173-176. doi: 10.1017/S0022149X0000024X.

Owen, I.L. (2005). Parasitic zoonoses in Papua New Guinea. J Helminthol. 79, pp. 1-14.

Pachucki, C.T., Levandowski, R.A., Brown, V.A., Sonnenkalb, B.H. and Vruno, M.J. (1984). American paragonimiasis treated with praziquantel. New England Journal of Medicine. 311, pp. 582-583.

Procop, G.W. (2009). North American paragonimiasis (caused by Paragonimus kellicoti) in the context of global paragonimiasis. Clinical Microbiology Reviews. 22, pp. 415-446.

Rim, H.J., Chang, Y.S., Lee, J.S., Joo, K.H., Suh, W.H. and Tsuji, M. (1981). Clinical evaluation of praziquantel (Embay 8440; Biltricide $\left.{ }^{\circledR}\right)$ in the treatment of Paragonimus westermani. Korean Journal of Parasitology. 19, pp. 27-37.

Ripert, C., Couprie, B., Moyou, R., Gaillard, F., Appriou, M. and Tribouley-Duret, J. (1992). Therapeutic effect of triclabendazole in patients with paragonimiasis in Cameroon: a pilot study. Transactions of the Royal Society of Tropical Medicine and Hygiene. 86, pp. 417.

Saborio, P., Lanzas, R., Arrita, G. and Arguedas, A. (1995). Paragonimus mexicanus pericarditis: Report of two cases and review of the literature. J Trop Med Hyg. 98, pp. 316-318.

Seo, B.S. (1978). Clinical Parasitology. Il-Cho-Kak, Seoul, Korea. pp. 244-256.

Shibahara, T., Nishida, H., Torii, M., Gyoten, J., Tsuboi, T. and Sakai, M. (1992). Experimental infection of wild boars with metacercariae of Paragonimus miyazakii (Trematoda: Troglotrematidae). Japan J Parasitol. 41, pp. $274-278$.

Singh, T.S., Singh, D.L. and Sugiyama, H. (2006). Possible discovery of Chinese lung fluke, Paragonimus skrjabini in Manipur, India. Southeast Asian Journal of Tropical Medicine and Public Health. 37, pp. 53-56.

Singh, T.S. and Sugiyama, H. (2008). Paragonimiasis in India: a newly emerging food borne parasitic disease. Clin Parasitol. 19, pp. 95. 
Singh, T.S., Sugiyama, H., Umehara, A., Hiese, S. and Khalo, K. (2009). Paragonimus heterotremus infection in Nagaland: a new focus of paragonimiasis in India. Indian J Med Microbiol. 27, pp. 123-127.

Song, C.C., Duan, Y.F., Shou, G.C. and Zhu, H. (1992). Effect of cobalt-60 irradiation on the infectivity of Paragonimus westermani metacercariae. Journal of Parasitology. 78, pp. 869-871.

Sugiyama, H., Singh, T.S. and Rangsiruji, A. (2013). Paragonimus. Molecular Detection of Human Parasitic Pathogens. (Liu, D., ed.). CRC Press, Taylor \&amp; Francis Group, LLC. Boca Raton, FL. pp. 423-435.

Sui, F., Shu-hua, X. and Catto, B.A. (1988). Clinical use of praziquantel in China. Parasitology Today. 4, pp. 312-315.

Toscano, C., Yu, S.H., Nunn, P. and Mott, K.E. (1994). Paragonimiasis and tuberculosis, diagnostic confusion: A review of the literature. Trop Dis Bull. 92, pp. R1-R26.

Udonski, J.K. (1989). Clinical field trials of praziquantel in pulmonary paragonimiasis due to Paragonimus uterobilateralis in endemic populations of the Igwun basin, Nigeria. Trop Med Parasitol. 40, pp. 65-68.

Waikagul, J. (2007). A new species of Paragonimus (Trematoda: Troglotrematidae) from a cat infected with metacercariae from mountain crabs Larnaudia larnaudia. Journal of Parasitology. 93, pp. 1496-1500.

Walker, M.D. and,. (2005). Neuroparasitic infections: cestodes, trematodes, and protozoans. Sem Neurol. 25, pp. $262-277$.

Wang, W., Blair, D., Min, T., Li, F. and Wang, D. (2011). Paragonimus worm from a New Guinea native in 1926. Asian Pacific Journal of Tropical Medicine. 4, pp. 76-78.

Weber, P., Büscher, G. and Büttner, D.W. (1988). The effects of triclabendazole on the lung fluke, Paragonimus uterobilateralis in the experimental host Sigmodon hispidus. Trop Med Parasitol. 39, pp. 322-324.

WHO,. (2015). Investing to overcome the global impact of neglected tropical disease: third WHO report on neglected diseases. WHO/HTM/NTD/2015.1. World Health Organization. Geneva, Switzerland.

WHO,. (2015). WHO estimates of the global burden of foodborne diseases: foodborne disease burden epidemiology reference group 2007-2015. World Health Organization. Geneva, Switzerland.

WHO,. (1995). Control of foodborne trematode infections, Report of a Study Group. WHO Techn. Rep. Ser. No. 849. World Health Organization. Geneva, Switzerland.

WHO,. (1989). Health guidelines for the use of waste water in aquaculture. WHO Techn. Rep. Ser. No. 778. World Health Organization. Geneva, Switzerland.

Williams, A.R. and Overbo, A. (2015). Unsafe return of human excreta to the environment: a literature review. The Water Institute at UNC. Chapel Hill, NC.

Yaemput, S., Dekumyoy, P. and Visiassuk, K. (1994). The natural first intermediate host of Paragonimus siamensis (Miyazaki and Wykoff, 1965) in Thailand. Southeast Asia J Trop Med Public Health. 25, pp. 284-290.

Yokogawa, M. (1969). Paragonimus and paragonimiasis. Advances in Parasitology. 7, pp. 375-387.

Yokogawa, M. (1965). Paragonimus and paragonimiasis. Advances in Parasitology. 3, pp. 99-158.

Yokogawa, M., Araki, K., Saito, K., Momose, T., Kimura, M., Suzuki, S. et al. (1974). Paragonimus miyazakii infections in man first found in Kanto district, Japan. Japanese Journal of Parasitology. 23, pp. 167-179.

Yokogawa, S., Cort, W.W. and Yokogawa, M. (1960). Paragonimus and paragonimiasis. Experimental Parasitology. 10, pp. 81-137, 139-205.

Ziegelbauer, K., Speich, B., Mäusezahl, D., Bos, R., Keiser, J. and Utzinger, J. (2012). Effect of sanitation on soil-transmitted helminth infection: systematic review and meta-analysis. PLOS Medicine. 9, pp. e1001162. 
Zhong, H.L., He, L.Y., Xu, Z.B. and Cao, W.J. (1981). Recent progress in studies of Paragonimus and paragonimiasis control in China. Chinese Medical Journal. 94, pp. 483-494. 